\title{
A SUPERAÇÃO DO AUTORITARISMO EM JOSÉ J. VEIGA OVERCOMING AUTHORITARIANISM IN JOSÉ J. VEIGA
}

\author{
Gabriel Gustavo dos Santos ${ }^{1}$ \\ Nerynei Meira Carneiro Bellini ${ }^{2}$
}

Resumo: José J. Veiga (1915-1999) foi, conforme atesta grande parte da crítica literária brasileira, um dos maiores e mais importantes escritores do país, de modo que em seu universo ficcional o leitor depara-se com críticas tenazes às mazelas sociais, aliadas a circunstâncias absurdas e insólitas. Em Sombras de Reis Barbudos de José J. Veiga, subjacente ao singelo enredo, o autor realiza crítica e denúncia tenazes à ditadura militar brasileira, ocorrida entre os anos de 1964 e 1985, por meio do emprego de metáforas e hipérboles habilmente entretecidas em uma obra fantástica. Há articulações relevantes tanto quanto à estruturação do fantástico literário como dos significados alusivos aos abusos da ditadura, denunciados por meio da literatura fantástica.

Palavras-chave: Veiga; denúncia; ditadura militar; fantástico.

Absubstract: José J. Veiga (1915-1999) was, as most of the Brazilian literary criticism attests, one of the largest and most important writers in the country, so that in his fictional universe the reader is faced with tenacious criticisms of social ills, allied absurd and unusual circumstances. In Sombras de Reis Barbudos by José J. Veiga, underlying to the simple plot, the author presents tenacious criticism and denouncement to the Brazilian military dictatorship that occurred between 1964 and 1985 through the use of metaphors and hyperboles skillfully interwoven in a fantastic work. There are relevant articulations as much as the structure of the literary fantastic as one of the allusive meanings to the abuses of the dictatorship, denounced by the fantastic literature.

Keywords: Veiga; denouncement; military dictatorship; fantastic.

1 Formado em Letras Português-Espanhol pela Universidade Estadual do Norte do Paraná (UENP). Especialização em Educação em Direitos Humanos pela FAVENI. E-mail: gabrielsantosps50@gmail.com

2 Doutora em Letras pela Universidade Estadual Paulista Júlio de Mesquita Filho (2004). Professora efetiva da Universidade Estadual do Norte do Paraná, Centro de Letras, Comunicação e Artes, de Jacarezinho. E-mail: nery@uenp.edu.com 


\section{APRESENTAÇÃO}

Este artigo, que é de caráter bibliográfico, busca estabelecer um diálogo entre a obra Sombra de Reis Barbudos (1972), de José J. Veiga, e o contexto histórico e político em que foi concebido: a ditadura militar. Além disso, também objetivamos discutir a respeito da função do fantástico literário, em seu sentido lato, entendido, aqui, como elemento insólito que foge à realidade, dentro do livro.

Nesse sentido, nosso método de pesquisa consiste na análise de trechos que contenham o insólito e/ou estabeleçam alguma relação com o já mencionado período vivenciado no Brasil. Para tal, analisamos a obra em tela à luz da teoria de Caserani (2006), Furtado (1980), Habert (1994), entre outros.

A pertinência de nosso estudo se revela pela importância da obra aqui abordada, que, mesmo após décadas de sua publicação, continua sendo contudente em suas críticas até os dias de hoje, infelizmente. Desse modo, nossa pesquisa se torna relevante em virtude de ser uma análise de uma obra atemporal, que não se encerra em dizer no ponto final, e que a cada releitura convida o leitor a novas reflexões.

\section{ANÁLISE DE SOMBRA DE REIS BARBUDOS}

José J. Veiga (1915-1999) foi, conforme atesta grande parte da crítica literária brasileira, um dos maiores e mais importantes escritores do país. Apesar de ter se formado em Direito (1943), atuou na maior parte de sua vida como jornalista, tradutor, contista e romancista. Em 1959, aos 45 anos, teve seu primeiro livro de ficção publicado, intitulado Os cavalinhos de Platiplanto. Esta obra de contos, assim inúmeras outras, rendeu ao autor diversos prêmios da crítica especializada, dos quais podemos citar: Prêmio Jabuti $(1981 ; 1983$; 1993) e Machado de Assis em 1997 (GLOBAL Editora Online).

Em seu universo ficcional o leitor depara-se com críticas tenazes às mazelas sociais, aliadas a circunstâncias absurdas e insólitas. A esse respeito, é preciso tecer um esclarecimento: quando abordarmos, neste artigo, os eventos de caráter insólito presentes na obra em discussão, os nomearemos de fantásticos, em seu sentido lato, como "aquilo que é produto da imaginação, que só existe como fantasia" (MICHAELIS Online); o fantástico, neste caso, pode ser tomado como sinônimo de insólito, que, segundo o mesmo dicionário, se refere ao que "não é habitual; anormal; extraordinário", ou seja, tudo aquilo que escapa à realidade.

Sombras de Reis Barbudos (primeira publicação em 1972) do escritor goiano José J. Veiga inicia-se a partir do recurso estético da analepse, ou seja, do "movimento temporal retrospectivo destinado a relatar eventos anteriores ao presente da ação e mesmo, em alguns casos, anteriores ao seu início" (REIS, 1988, p. 230). Por meio do emprego da analepse, relacionada à focalização vigente, objetiva-se recuperar acontecimentos passados, a partir da perspectiva de um protagonista menino. Com isso, atribui-se coerência interna à narrativa e, especificamente, ao sobrenatural instituído.

Pela ativação da memória de um narrador que vivenciou os fatos narrados, o leitor conhece Taitara e toma ciência de sua desolação e abandono, à semelhança de uma cidade 
fantasma. Logo de início, esse tipo de narrador cabe bem aos propósitos de aguçar o interesse do leitor:

Já estou cansado de bater pernas pelos lugares de sempre e só ver essa tristeza de casas vazias, janelas e portas batendo ao vento, mato crescendo nos pátios antes tão bem tratados, lagartixas passeando atrevidas até em cima dos móveis, gambás fazendo ninho nos fogões apagados, se vingando do tempo em que corriam perigo até no fundo dos quintais (VEIGA, 1995, p. 2)

A descrição do lugarejo sugere um ambiente misterioso e intrigante, pois se desconhece o fato que impulsionou os moradores a deixarem, às pressas, suas casas em uma pacata e tranquila cidade. O episódio insinua a presença de algo perigoso que ameaçava até os gambás. Somam-se a isso a estranha pessoa do tio Baltazar e a instalação de uma indústria denominada Companhia Melhoramentos do Brasil. Pela ótica e voz do narrador Lucas relata-se que, após esses fatos, houve uma reviravolta na rotina de Taitara.

Isto porque, ao ser estabelecida a Companhia, os moradores experimentam uma ilusória prosperidade econômica que desencadeia um consumo exacerbado e nocivo. O engodo do progresso e da liberdade vem à tona com a enfermidade e partida de Baltazar, presidente da Companhia, quando o autoritarismo dos líderes locais se revela em toda sua pujança hostil e opressora. Uma das evidências desta dominação é o repentino surgimento de muros que cruzam as ruas da cidade.

De repente, os muros, esses muros. Da noite para o dia eles brotaram assim retos, curvos, quebrados, descendo, subindo, dividindo as ruas ao meio conforme o traçado, separando amigos, tapando vistas, escurecendo, abafando. Até hoje não sabemos se eles foram construídos aí mesmo nos lugares ou trazidos de longe já prontos e fincados aí. Com tanto muro para encarar quando estaríamos parados e rodear quando tínhamos de andar, a vida estava ficando cada vez mais difícil para todos. (VEIGA, 1995, p. 27)

O narrador afirma que quem mandou construir os muros, convertendo a cidade em um verdadeiro labirinto, foram os donos da Companhia e estes o fazem logo após o golpe dado em Baltazar. A assertiva de que houve um golpe na empresa e de que seu presidente fora deposto, conduz-nos a inferir sobre a proximidade semântica com dados históricos extrínsecos à narrativa, em específico, o golpe militar em 1964, no Brasil, quando se depôs o presidente João Goulart.

A nosso ver, a personagem Baltazar, presidente da Companhia Melhoramentos do Brasil, vai ao encontro da figura histórica de Goulart, presidente do Brasil na época, um país que urgia por melhorias econômicas e sociais. A similaridade fonética entre os nomes de Baltazar e Goulart indicia essa leitura, além do fato de ocuparem o mesmo cargo, isto é, a presidência.

A respeito desses fatos históricos, a professora de História e pesquisadora Nadine Habert, em seu livro A década de 70, afirma que: 
A década de 70 esteve mergulhada numa ditadura militar que não começou nem terminou naqueles anos. O governo Médici foi a consolidação de uma trajetória cujas pontas mais próximas estavam no golpe civil e militar que depôs o presidente João Goulart (Jango) em março de 1964, instaurando uma ditadura militar que viria a durar 21 anos. (HABERT, 1994, p. 8)

Em Sombras de Reis Barbudos, o espaço da Companhia alude, sobretudo, à máquina governamental do período ditatorial no Brasil que oprimia pessoas e cerceava seus direitos, pois "o governo poderia, entre várias atribuições, suspender as garantias individuais e públicas e atribuir amplos poderes às Forças Armadas” (HABERT, 1994, p. 51). O impacto brusco e cruel - causado pelo golpe de 64 e pela dominação dos militares - é simbolizado nesta obra pelo surgimento inesperado dos muros, que indicia um processo gradativo de restrição dos direitos civis.

A construção dos muros revela a impossibilidade cruel de fazer valer o direito de ir e vir dos habitantes de Taitara e as demais proibições implicam limitações que atingem o âmago das pessoas, ou seja, a satisfação de viver. Além disso, a cidade se converte em um verdadeiro labirinto quase impossível de ser transposto: “(...) os muros, esses muros. Da noite para o dia eles brotaram assim retos, curvos, quebrados, descendo, subindo, dividindo as ruas ao meio conforme o traçado (...)" (VEIGA, 1995, p. 27).

Em Sombras de Reis Barbudos entendemos que a construção labiríntica da cidade simboliza a opressão e a dominação de governantes pérfidos. Além disso, pode significar recalques, como, limitações e temores que paralisam as atitudes e as decisões humanas. Para se combater, com êxito, tais adversidades, sejam elas de natureza física ou psíquica, social ou política, impõe-se uma decisão corajosa do homem.

Paradoxalmente, a presença opressora dos "muros", ou ainda, o enfrentamento dos entraves cerceadores é que impulsiona o ser humano a agir na direção de soluções plausíveis. Para tanto, faz-se necessário "visualizar" e contar com o auxílio daquilo que se encontra além dos problemas imediatos, isto é, o sobrenatural.

O provável labirinto em Sombras de Reis Barbudos engendra uma metáfora cronotópica alusiva à desesperança que se instala na cidade sem perspectiva de mudança até os habitantes saberem da chegada do mágico Uzk. Na concepção do narrador Lucas e de outras personagens, as habilidades incomuns do artista circense poderiam proporcionar divertimento e alegria aos moradores de Taitara, apenas pelo espetáculo apresentado no palco. Porém, o que aguça em demasia a curiosidade e o desejo sobre a vinda de Uzk diz respeito aos outros números artísticos insólitos que executava, como, por exemplo, o voo, a transformação de velas em joias, além de outros. O protagonista pretende constatar tudo isso aguardando ansioso pela vinda do mágico, divulgada com antecedência.

Infere-se que as expectativas frustradas dos taitarenos, em particular as de Lucas, são renovadas quando da hipótese de o mágico participar de suas rotinas insípidas e manipuláveis.

Por essa propaganda falada ficamos sabendo que o Grande Uzk vinha do Oriente (bom começo; o bom mágico precisa vir de longe), que suas mágicas mais pa- 
reciam milagres (ele fazia na hora tudo o que o público pedisse - transformava pedra em pássaro, areia em água, estrume em ouro e vice-versa se alguém quisesse); e que além das mágicas que fazia no palco ele sabia outras que só podiam ser vistas de perto, como uma na mesa de bilhar, tão incrível que metia medo. (VEIGA, 1995, p. 52)

O mágico é originário do Oriente e traz com ele todo o encantamento que esse local conota. Em meio a uma realidade hostil e adversa, a vinda da magia representa uma pausa, um refrigério, que renovará as forças e as esperanças dos taitarenos no afã de superarem os obstáculos. Essa proposição é reiterada até em termos discursivos, conforme se verifica no título que recebe o capítulo correspondente: "Pausa para um Mágico".

Quanto à hipótese de que a chegada do mágico implicaria alterações significativas nos fatos vigentes, é manifestada no enredo pela possível suspeita da Companhia Melhoramentos. Valendo-se do ponto de vista do narrador, é proposto que a demora na chegada de Uzk deve-se a um impedimento da Companhia. Esta, por fim, autoriza o acontecimento, provavelmente, tido como inofensivo a suas imposições e interditos.

O efeito da magia coaduna com proposições de Zilberman sobre o caráter emancipatório da fantasia (no sentido lato), implícito no romance de Veiga a partir do ponto de vista de um narrador infantil e reabsorvido na recepção do leitor. Por isso, com base nos símbolos narrativos de Sombras de Reis Barbudos, pode-se inferir que ao imaginário se confere o poder de revitalizar algo inerte e desvalido, de despertar expectativas promissoras no ser humano e, consequentemente, de impulsioná-lo à superação dos empecilhos existenciais, sociais e políticos.

Por certo, a estada do mágico na cidade e o contato dos taitarenos com o sobrenatural desencadearam atitudes também incomuns, atenuantes da situação coercitiva na qual se encontravam. Não é aleatório, portanto, que só após as extraordinárias demonstrações de Uzk, desafios a qualquer limitação humana, os moradores começaram a alçar voos. A mágica, desse modo, extrapola as apresentações momentâneas no "palco do circo" e passa a incorporar o "palco da existência". Por isso, voar torna-se parte do cotidiano dos habitantes de Taitara que, aos poucos, vão adquirindo a habilidade naturalmente.

O episódio que elabora o fato da magia de Uzk proporcionar, além de entretenimento, amplitudes e superações aos habitantes de Taitara, conduz a uma leitura metalinguística no que tange à composição estética do insólito, bem como de seus efeitos no leitor. Na ficção se constata a existência de uma cidade abafada por muros, cujos moradores sofrem proibições descabidas e hostis e, no contexto histórico, países com seus respectivos cidadãos foram (e muitos ainda são) vítimas de leis ditatoriais ultrajantes.

Quanto à relação entre literatura e realidade histórica e política, José J. Veiga expôs - em entrevista concedida a José Castello, na ocasião articulista do jornal O Estado de S. Paulo - que "os militares também foram responsáveis pelo tipo de ficção que despontou na América Latina, na década de cinquenta, ou seja, o fantástico" (aqui também podemos entender o termo fantástico em sentido lato, como algo que foge à racionalidade). O escritor refere-se às arbitrariedades e aos desmandos absurdos e inadmissíveis efetuados por gover- 
nantes da época os quais compeliram intelectuais e artistas, inconformados com tamanha opressão, a expressarem sua repulsa e indignação ao sistema vigente por meio da simbologia da linguagem.

Em se tratando das estratégias do fantástico em termos de recursos empreendidos na elaboração textual e seus efeitos semânticos, Remo Ceserani afirma, em seu livro O fantástico (2006), com tradução de Nilton Cezar Tridapalli, que:

A presença de elementos de paródia e de discussão metanarrativa sobre os modos e sobre os códigos da narração parece uma indicação e uma sugestão da ambiguidade de toda a operação estratégica: a literatura fantástica finge contar uma história para poder contar outra. (CESERANI, 2006, p.102)

Nas entrelinhas de Sombras de Reis Barbudos é possível apreender as alusões que o escritor tece ao papel da literatura enquanto promotora de reflexões que induzem o leitor a reconhecer-se como ser humano e cidadão, assim como responsável por questionamentos que o fazem superar interditos impostos arbitrariamente e empenhar-se na tomada de ações decisórias para vencer desmandos e repressões políticas.

A despeito das situações adversas e das constantes reprimendas, valendo-se do exercício figurativo da linguagem, foi possível "ludibriar" a censura e o interdito e verbalizar assertivas críticas. Acima de tudo, a magia da literatura, ou, ainda, o insólito literário se reveste da capacidade de divertir o leitor, ao mesmo tempo em que lhe propõe mudanças e superações. Pelo veio do imaginário, exercita-se a liberdade de "voar para além das barreiras impostas por líderes déspotas".

Neste momento da análise, é possível inferir sobre outro significativo elemento emancipatório, ou seja, o voo dos moradores. A fim de burlar a proibição de não saltar os muros e, ainda, de escapar desse labiríntico local, alguns taitarenos principiam a altear voos, coibidos depois. Proibição essa sem êxito, pois os moradores de Taitara libertaram-se pelo voo.

Pois se o homem passava voando bem na minha frente, justamente diante da parte aberta da torre! Foi rápido, mas deu para ver. Ia deitadinho como nadando, só que não dava braçadas, apenas mexia discretamente com os braços, e me pareceu que tinha um cigarro aceso na boca, se não era cigarro era um canudinho outro que também soltava fumaça. (VEIGA, 1995, p. 117)

É possível inquirir se a questão do voo implicaria uma atitude escapista com refúgio na fantasia. Acredita-se no oposto, pois, a partir dessa prática e mirada, ampliam-se os horizontes dos moradores, possibilitando-lhes visualizar outras realidades, e, consequentemente, superar os bloqueios políticos, sociais e econômicos.

Os moradores de Taitara conseguem enfraquecer e burlar as imposições estabelecidas pela Companhia, valendo-se do insólito ato de voar. Várias pessoas começam a voar acima da sufocante cidade, pairando sobre os obstáculos sociais criados pelos detentores do poder e não há nada que possa impedi-los: "Hoje ninguém estranha, todo mundo está voando apesar da proibição, só não voa quem não quer ou não pode ou tem medo" (VEIGA, 1995, p.131). 
Por meio da metáfora do voo, o autor sugere, a despeito do período difícil marcado pelo regime militar, a necessidade do ser humano em continuar a sonhar e ansiar por mudanças com fins à superação da realidade aviltante. Em Sombras de Reis Barbudos, a possibilidade de divisar outro universo ocorre pela ótica do narrador, configurando um hábil procedimento estético, Veiga traça a focalização pelo prisma do imaginário infantil.

Com isso, relativiza-se a ideia cristalizada da primazia do pensamento racional na resolução de problemas (em termos de procedimento estético, ocorre a desautomatização do objeto, conforme afirmou o formalista russo Chklovski). Portanto, sugere-se que o olhar visionário do menino é mais coerente do que o inconsequente mundo adulto estruturado pelo, no mínimo ilógico, sistema político e econômico em vigor.

A construção espacial de Taitara, hiperbolicamente entremeada por muros, simboliza, além dos aspectos sociopolíticos, concepções existenciais. Em uma primeira instância, os muros podem aludir aos conflitos do adolescente, em transição etária, que se percebe em um mundo adulto impregnado por normas e conceitos cerceadores.

Além disso, o espaço fechado dessa cidade pode aludir à intensa alienação do homem moderno que, mesmo tendo acesso a uma gama de informações, prescinde de contatos presenciais, isolando-se diante de uma máquina; ignorando o outro, desconhecendo-se a si mesmo e perdendo-se em um mundo caótico, à semelhança do ocorrido em Taitara.

Os muros impedem a locomoção, restringem os relacionamentos e limitam o campo de visão dos habitantes. A instauração abrupta e a permanência indesejável de tais impedimentos conotam efeitos nocivos desencadeados na cidade, embora a existência dos muros nem sempre implique resultados desfavoráveis. Ironicamente, é em razão da necessidade compulsória de se locomover, ou ainda, de encontrar alternativas de fuga em um espaço exíguo, interseccionado por muros, que o taitareno supera a si mesmo, desenvolve suas potencialidades e ultrapassa as barreiras impostas.

A partir do bloqueio espacial representado pela alusão hiperbólica dos muros que impedem a visão dos moradores, a narrativa desencadeia, quase que como uma consequência da necessidade de "libertação do labirinto", outra metáfora particularmente intensa em textos de Veiga, isto é, "o ver ao longe". Isto porque, o fato de viverem em uma cidade murada sem perspectivas de liberdade, induz os taitarenos a buscarem o uso de objetos que lhes ampliem a visão.

Tinha chegado o ponto em que o nosso único consolo era subir a um lugar alto e olhar os campos e estradas além de nossas divisas, onde não vigoram ainda os regulamentos da Companhia. Nos dias claros podíamos ver animais pastando, gente passando, e quem tinha lunetas e binóculos guardados do tempo da invasão dos urubus via até o vento balançando folhas, um vento diferente, mais solto, sem muros para detê-lo. Esse passatempo de olhar para longe estava viciando um número cada vez maior de pessoas. Acho que fazíamos isso como quem olha uma festa pelo buraco da fechadura, imaginando mais do que vendo. (VEIGA, 1995, p. 116)

A metáfora do olhar pode sugerir a relevância de se almejar uma visão mais ampla da realidade, ou seja, um conhecimento maior do que existe no mundo aparente. Ainda há um 
apelo ao ser humano para redirecionar seu olhar muito além de seus entraves e, assim, vislumbrar soluções. A plena dimensão do ver remete a um conhecimento das possibilidades humanas, muitas vezes, escamoteadas por circunstâncias adversas e por valores corrosivos.

Neste estudo, infere-se a intenção implícita do autor em desvelar ao leitor a essencial descoberta, ou seja, a importância de imaginar, de sonhar, de acreditar em superações, apesar das situações adversas. A pluralidade de leituras proporcionadas em Sombras de Reis Barbudos parece indicar a necessidade ontológica de se vislumbrarem outras realidades, atingir outras dimensões, enfim, apreender outros sentidos à existência.

Esse romance remete ao procedimento ficcional da narrativa fantástica de combinar dados da realidade empírica com elementos inusitados, evidentes na elaboração da focalização, do espaço, da personagem do mágico e na narração de fatos insólitos. A obra reitera o mecanismo pelo qual o leitor deve ver, deve assimilar o sobrenatural, isto é, não por meio de explicação lógica, mas utilizando a "luneta do imaginário".

Filipe Furtado, em seus estudos sobre a construção literária do fantástico, destaca a elaboração de um espaço ficcional híbrido, no qual se faz um trabalho específico com a linguagem e descreve-se um ambiente verista, próximo da realidade aparente, entremeado, contudo, por recorrências e seres inexplicáveis. Em seus termos, o teórico afirma que, a fim de engendrar o fantástico textual, é necessário "evocar um espaço híbrido, indefinido, que, aparentando, sobretudo, representar o mundo real, contenha indícios da própria subversão deste e a deixe insinuar-se aos poucos" (FURTADO, 1980, p. 133).

Tal proposição é perceptível na caracterização híbrida da cidade de Taitara, pois representa, esteticamente, um lugar verossímil, à semelhança de uma cidade interiorana, que, repentinamente, é invadida pelo insólito, ou ainda, pelo inexplicável. O insólito aqui reside mais em termos da simbologia de ações narrativas do que da descrição de um ser irreal; por essa razão, instala-se uma intrusão cruel de algo inesperado em um ambiente pacato e familiar. Em Taitara os muros abafam e restringem os espaços, de início, físicos e particulares, mas, depois, sociais e interpessoais.

A gradativa invasão se faz sentir em Taitara, pois, conforme visto em segmentos das análises, aos poucos a Companhia, que não se sabe de quem, vai impondo interditos excedidos pela instalação de muros os quais entrecortam as ruas. O ponto de vista do narrador Lucas logo indicia essa gradação: "é curioso como certas coisas vão acontecendo em volta da gente sem a gente perceber, e quando vê já estão aí firmes e antigas" (VEIGA, 1995, p. 7). Os espaços dos taitarenos são obstruídos e restringidos paulatinamente, até se chegar a uma situação extrema e insustentável de cerceamento do andar, por isso, os moradores encontram no voo a única alternativa plausível para burlar a opressão vigente.

Em Taitara, as situações hostis e desumanas são impostas por um poder político déspota que, estrategicamente, não é identificável na obra, contudo é amplamente sugestivo devido ao trabalho peculiar com a linguagem, entremeada por símbolos narrativos inerentes ao fantástico literário. Tal omissão ocorre, provavelmente, porque a primeira publicação de Sombras de Reis Barbudos, em 1972, ocorreu em plena ditadura militar no Brasil. No romance, a privação da liberdade a que são submetidas às personagens sugere não apenas restrições geográficas, mas, especialmente, impropérios políticos. 


\section{CONSIDERAÇÕES FINAIS}

Em Sombras de Reis Barbudos a ênfase estética recai sobre o espaço e seus componentes e revela, assim, eficiente função enquanto caracterizador de narrativas insólitas que imbricam realidades. A construção espacial, sobretudo, promove a denúncia e a crítica de degradantes circunstâncias sociais e políticas opressoras. Por essa razão, ao se limitarem os locais descritos por muros ou por ocupações, a narrativa infere ações coercitivas de um poder déspota que impõe medidas arbitrárias, bloqueando a liberdade de agir dos indivíduos.

A narrativa literária, finalmente, por meio de hábil urdidura dos componentes narrativos, da presença fulcral do insólito, articulado por recursos de linguagem, como a metáfora e a hipérbole, gera múltiplos sentidos. Por isso, é viável a leitura de que essa produção indicia o empenho cognitivo e, até mesmo, físico do ser humano em ultrapassar obstáculos, arbitrariamente impostos, no esforço supremo de não esmorecer, a despeito das circunstâncias hostis. Parece, portanto, haver um desejo intenso do indivíduo em continuar agindo rumo a superações dos entraves e interditos, ainda que, em muitos momentos, só lhe reste visualizar "voos longínquos".

\section{REFERÊNCIAS}

CASTELLO, José. José J. Veiga defende estilo despojado. O Estado de S. Paulo, São Paulo, D 3, Caderno 2, out. 1997.

CESERANI, Remo. O fantástico. Curitiba: Ed. UFPR, 2006.

CHKLOVSKI, Vladimir. A arte como procedimento. In: VÁRIOS. Teoria da Literatura: formalistas russos. Porto Alegre: Ed. Globo, 1971. p. 39-56.

FURTADO, Filipe. A construção do fantástico na narrativa. Lisboa: Horizonte Universitário, 1980.

GLOBAL, Editora. Biografia de José J. Veiga. Disponível em: <https://globaleditora.com.br/autores/ biografia/?id=1777>. Acesso em: 14 de agosto de 2019.

HABERT, Nadine. A década de 70: apogeu e crise da ditadura militar brasileira. São Paulo: Editora Ática, 1994.

MICHAELIS, Dicionário. Disponível em: <https://michaelis.uol.com.br/>. Acesso em: 14 de agosto de 2019.

REIS, Carlos e LOPES, A. C. M. Dicionário de teoria da narrativa. São Paulo: Ática, 1988.

VEIGA, José J. Sombras de Reis Barbudos. 21ª ed. Rio de Janeiro: Bertrand Brasil, 1995. 
ZILBERMAN, R. O verismo e a fantasia das crianças. In: A literatura infantil na escola. $4^{\mathrm{a}}$ ed. rev. e ampl. São Paulo: Global, 1985. p. 87-91. 